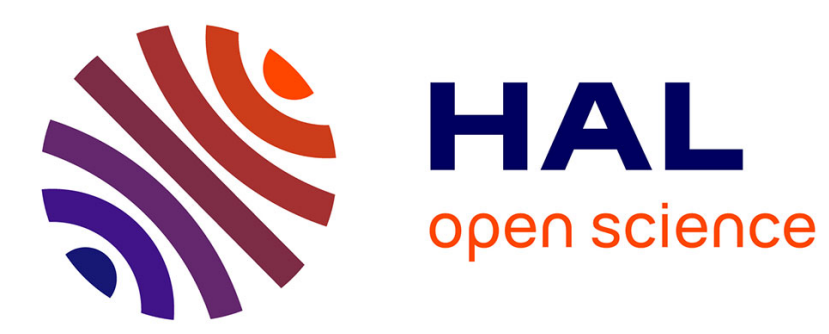

\title{
The Accuracy Of Digital Infrared Imaging For Breast Cancer Detection In Women Undergoing Breast Biopsy
}

G.C Wishart, M Campisi, M .Boswell, D Chapman, V Shackleton, S Iddles, A Hallett, P.D. Britton

\section{- To cite this version:}

G.C Wishart, M Campisi, M .Boswell, D Chapman, V Shackleton, et al.. The Accuracy Of Digital Infrared Imaging For Breast Cancer Detection In Women Undergoing Breast Biopsy. EJSO - European Journal of Surgical Oncology, 2010, 36 (6), pp.535. 10.1016/j.ejso.2010.04.003 . hal-00599228

\section{HAL Id: hal-00599228 https://hal.science/hal-00599228}

Submitted on 9 Jun 2011

HAL is a multi-disciplinary open access archive for the deposit and dissemination of scientific research documents, whether they are published or not. The documents may come from teaching and research institutions in France or abroad, or from public or private research centers.
L'archive ouverte pluridisciplinaire HAL, est destinée au dépôt et à la diffusion de documents scientifiques de niveau recherche, publiés ou non, émanant des établissements d'enseignement et de recherche français ou étrangers, des laboratoires publics ou privés. 


\section{Accepted Manuscript}

Title: The Accuracy Of Digital Infrared Imaging For Breast Cancer Detection In Women Undergoing Breast Biopsy

Authors: G.C Wishart, M Campisi, M .Boswell, D Chapman, V Shackleton, S Iddles, A Hallett, P.D. Britton

PII: S0748-7983(10)00090-9

DOI: 10.1016/j.ejso.2010.04.003

Reference: YEJSO 2952

To appear in: European Journal of Surgical Oncology

Received Date: 3 November 2009

Revised Date: 11 February 2010

Accepted Date: 5 April 2010

Please cite this article as: Wishart GC, Campisi M,.Boswell M, Chapman D, Shackleton V, Iddles S, Hallett A, Britton PD. The Accuracy Of Digital Infrared Imaging For Breast Cancer Detection In Women Undergoing Breast Biopsy, European Journal of Surgical Oncology (2010), doi: 10.1016/ j.ejso.2010.04.003

This is a PDF file of an unedited manuscript that has been accepted for publication. As a service to our customers we are providing this early version of the manuscript. The manuscript will undergo copyediting, typesetting, and review of the resulting proof before it is published in its final form. Please note that during the production process errors may be discovered which could affect the content, and all legal disclaimers that apply to the journal pertain. 
THE ACCURACY OF DIGITAL INFRARED IMAGING FOR BREAST CANCER DETECTION IN WOMEN UNDERGOING BREAST BIOPSY.

\section{GC Wishart ${ }^{\mathrm{a}, \mathrm{b}, \mathrm{c}}$, M Campisi ${ }^{\mathrm{d}}$, M Boswell ${ }^{\mathrm{a}}$, D Chapman ${ }^{\mathrm{a}}$, V Shackleton ${ }^{\mathrm{a}}$, S Iddles ${ }^{\mathrm{a}}$, A Hallett ${ }^{\mathrm{a}}$, PD Britton ${ }^{\mathrm{a}, \mathrm{b}}$}

${ }^{a}$ Cambridge Breast Unit, Addenbrooke's Hospital, Hills Road, Cambridge, CB2 2QQ, UK.

b NIHR Cambridge Biomedical Research Centre, Addenbrooke's Hospital, Hills Road, Cambridge, CB2 2QQ, UK.

${ }^{\mathrm{c}}$ Faculty of Health \& Social Care, Anglia Ruskin University, East Road, Cambridge, UK.

${ }^{\mathrm{d}}$ Faculty of Electrical \& Computer Engineering, Polytechnic Institute of New York University, New York, USA.

\section{Correspondence to:}

Prof GC Wishart

Consultant Breast \& Endocrine Surgeon

Cambridge Breast Unit

Box 97

Addenbrooke's Hospital

Hills Road

Cambridge

CB2 2QQ

Tel: $\quad 01223216315$

Fax: 01223257219

Email: gordon.wishart@addenbrookes.nhs.uk

Key words: Breast cancer; diagnostic imaging; thermography, digital infrared imaging. 


\section{ABSTRACT}

\section{Background}

Mammography has a lower sensitivity for breast cancer detection in younger women and those with dense breasts. Recent improvements in digital infrared breast imaging suggest there may be a role for this technology and we have studied its performance in 100 women prior to breast needle core biopsy (CB).

\section{Methods}

All patients were imaged using a digital infrared breast (DIB) scan (Sentinel BreastScan ${ }^{\mathrm{TM}}$ ) prior to breast biopsy. Analysis of the infrared scans was performed, blinded to biopsy results, in four different ways: Sentinel screening report, Sentinel artificial intelligence (neural network), expert manual review and NoTouch BreastScan a novel artificial intelligence programme.

\section{Results}

Of 106 biopsies performed in 100 women 65 were malignant and 41 were benign. Sensitivity of Sentinel screening (53\%) and Sentinel neural network (48\%) was low but analysis with NoTouch software (70\%) was much closer to expert manual review (78\%). Sensitivity (78\%) and specificity (75\%) using NoTouch BreastScan were higher in women under 50 and the combination of mammography and DIB, with NoTouch interpretation, in this age group resulted in a sensitivity of $89 \%$.

\section{Conclusion}

DIB using NoTouch is an effective adjunctive test for breast cancer detection in women under 70 and appears to be particularly effective in women under 50 where maximal sensitivity (78\%) and specificity (75\%) were observed. The combined sensitivity of NoTouch BreastScan and mammography in women under 50 was encouraging at $89 \%$, suggesting a potential way forward for a dual imaging approach in this younger age group. 


\section{INTRODUCTION}

Breast cancer is the most common female cancer with more than 45,000 cases diagnosed per annum in the UK. Early detection of breast cancer is associated with improved survival. A recent meta-analysis of over 500,000 women observed a 15$20 \%$ reduction in breast cancer mortality as a result of screening mammography [1]. Screen-detected cancers are more likely to be smaller, better differentiated and node negative but several recent studies have shown that screen detection remains an independent prognostic factor after adjustment for stage at presentation [2, 3, 4] Currently the UK breast screening programme offers 3-yearly mammography to women aged 50-70 and, in addition, mammography is a key tool in the investigation of symptomatic disease.

Despite the comparative success of mammography, there is a need for ongoing research to increase the sensitivity of breast cancer detection, especially in younger women. Although mammography is currently considered to be the "gold standard" technology for the diagnosis of breast cancer the performance of this procedure is less in younger women and relates to the difficulty of imaging dense breast tissue [5] and film interpretation. For this reason, continual attempts are being made to develop new imaging techniques to replace or complement mammography.

As long as 40 years ago, temperature differences on the breast surface, obtained with infrared hardware, were postulated as having relevance for breast cancer diagnosis [6]. These early studies, using what is now considered primitive thermography technology, showed promise as a diagnostic tool, but they were discredited for multiple reasons including a high degree of subjectivity as well as a high rate of false positives and false negatives.

Recent improvements in digital infrared imaging by the US military, as well as the ability to analyse images with artificial intelligence software, has led to the resurgence of this technique as a potential diagnostic breast imaging tool. This is supported by recognition that many breast cancers are associated with angiogenesis, a feature associated with the up to $86 \%$ of screen-detected and impalpable cancers [7]. A recent study has shown that when state-of-the-art infrared technology was combined with 
advanced computer hardware and software technology, the sensitivity for breast cancer detection was $97 \%$ in 92 patients undergoing breast biopsy [8].

In this study we have assessed the effectiveness of digital infrared imaging captured using Sentinel BreastScan ${ }^{\mathrm{TM}}$ (Infrared Sciences Corp., Bohemia, NY, USA) and compared the computer-generated report from this system with expert manual image review as well as a new software programme currently under development called NoTouch BreastScan. 


\section{PATIENTS AND METHODS}

\section{Patient eligibility}

Between June 2007 and January 2009, a total of 113 patients scheduled for CB, following detection of an abnormality on clinical examination or breast imaging (mammography, ultrasound or magnetic resonance imaging - MRI), were recruited to this study conducted in the Cambridge Breast Unit, Addenbrooke's Hospital. All patients gave informed consent to participate in this study which had approval from the local Research Ethics Committee. Patients with previous breast cancer surgery or treatment, patients with loss of one or both nipples, patients over $113 \mathrm{~kg}$ in weight and patients with acute breast inflammation were excluded.

\section{Digital infrared image capture}

After obtaining informed consent all patients were imaged using Sentinel BreastScan ${ }^{\mathrm{TM}}$, prior to their scheduled CB. The raw data for each patient were stored for future analysis and correlation with the biopsy report. The research clinician performing the breast scan was blinded to the results of the mammogram and other imaging results and the patient was blinded to the infrared report.

The examination was performed with the patient disrobed to the waist and appropriately positioned in an ergonomic chair with arms supported at eye level. Temperature controlled air flow was then directed at the breasts for approximately 5 minutes while the infrared camera recorded serial skin surface temperatures for a total of 250 individual frames. The stored images were uploaded into the computer software designed to extract specific thermal parameters, including a variety of temperature differences and thermal symmetry measurements. The software also focused on areas of the breasts that exhibited abnormal cooling patterns and assigned these sites with a colour code. The combination of these parameters was calculated for risk in a weighted "evaluation" algorithm by the proprietary software.

\section{Data analysis}

The data were analysed in four different ways. The computer analysed the raw data using 'artificial intelligence' and produced a "Patient Report" showing the results of the test. Sentinel BreastScan measures seven temperature parameters. Of the seven, four are comparison parameters that compare the left breast and right breast. The 
remainder identify excess heat in each individual breast. The overall score of a Sentinel BreastScan consists of sum of these those parameters that show as "high". In addition, a separate score known as a "Neural Network Score" is indicated on the Sentinel BreastScan. An overall risk score was determined by the software in screening mode giving a score from 0-5. A score of 0 was considered normal and a score of 1-5 was considered abnormal. A second score was provided by the artificial neural network to give a positive or negative finding. The images were also reviewed by an independent thermography expert, who was informed of the biopsy site but not the final pathology results, who then analysed this specific area on the infrared scan to determine if the scan was positive or negative. Lastly, these same images were interpreted using a novel artificial intelligence programme called NoTouch BreastScan. NoTouch BreastScan measures the same parameters as Sentinel BreastScan, however the algorithms identifying abnormalities have been modified. In addition, each parameter measured by NoTouch BreastScan is normalised to a score of 0 to 10 . The Overall Score reported by NoTouch is a proprietary algorithm that considers the results of each measurement and the significance of each result to arrive at an overall score of 0 to 10 . A patient with a score of more than 3 was considered abnormal. 


\section{RESULTS}

\section{Patient and tumour characteristics}

The study recruited 113 patients who underwent infrared imaging prior to biopsy. All patients presented either with a lump on clinical breast examination or an abnormality on screening mammography. Of these, 13 (benign, $n=5$; malignant, $n=8$ ) were excluded due to lack of image focus or inadequate coverage of the breast tissue on formal review of the scan quality. This took place before formal expert review and reporting of the scans.

The results are therefore based on a total of 106 biopsies performed in 100 women with an average age of 57 (range 33-87). Of the 106 biopsies 65 were malignant (invasive: $n=62$; in situ: $n=3$ ) and 41 were benign. Of the 65 patients with a malignant biopsy, 42 presented following routine mammographic screening. The 62 invasive cancers were graded as I ( $\mathrm{n}=13)$, II $(\mathrm{n}=35)$ and III $(\mathrm{n}=14)$ and the mean invasive tumour size was 19mm (range 1-48mm). Of the 62 invasive cancers 9 were associated with lymphovascular invasion and 57 were oestrogen receptor positive. Benign biopsy results included fibroadenoma $(n=22)$, fibrocystic disease $(n=5)$, sclerosing adenosis $(n=2)$, fat necrosis $(n=2)$, normal breast tissue $(n=2)$, and a single case each of hamartoma, inflammation, breast cyst, pseudoangiomatous stromal hyperplasia (PASH), papilloma, fibrous tissue, duct ectasia and radial scar.

\section{Infrared imaging results}

The overall scores in screening mode for 65 women with breast cancer are shown in Table I. Of these 65 cancers, 30 had a normal score of 0 . All 12 women $>70$ years of age had a malignant biopsy result on final pathology and in this group sensitivity was low with all methods of interpretation used (Sentinel BreastScan 33\%; expert manual review $=42 \%$; NoTouch BreastScan=42\%). Sensitivity, specificity, positive predictive value (PPV) and negative predictive value (NPV) are shown by age group for Sentinel screening mode, neural network, expert manual review and NoTouch software in Table II. Sensitivity of Sentinel screening (53\%) and neural network (48\%) was low but analysis with NoTouch software (70\%) was much closer to expert manual review (78\%). The sensitivity of mammography overall for breast cancer detection was $89 \%$. The sensitivity and specificity of breast ultrasound in this cohort were $90 \%$ and $95 \%$ respectively. 
Exclusion of women over 70 years of age increased the sensitivity for all modalities by $2-5 \%$ (Table II). Sensitivity of NoTouch was higher in the $<50$ age group (78\%) compared with the 50-70 age group (72\%), with a large corresponding increase in specificity from $37 \%$ to $75 \%$. In the under 50 age group NoTouch had the same sensitivity as mammography (78\%) but the combined sensitivity of NoTouch and mammography for breast cancer detection was higher at $89 \%$.

The sensitivity of IR imaging by tumour grade, type, size, nodal status and presence of lymphovascular invasion is shown in Table III. . 


\section{DISCUSSION}

The initial results of this study, based on digital infrared imaging, captured using Sentinel Breast Scan ${ }^{\mathrm{TM}}$ (Infrared Sciences Corp., Bohemia, NY, USA), show a low sensitivity for both the screening mode (53\%) and neural network (48\%) which does not concur with previously published data by Arora et al [8] (97\%). This may be partly explained by the fact that 42 of the 65 cancers in this series are screen-detected, with an average tumour size of $19 \mathrm{~mm}$, compared to a median tumour size of $14 \mathrm{~m} \mathrm{~mm}$ (range 5-140mm) in the Arora series. Since the analysis in our study was carried out blinded to the final pathology results these updated findings are likely to be more reliable and robust. Although 13 of 113 scans were excluded from the final analysis, due to lack of image focus or inadequate coverage of the breast tissue, these were operator errors due to patient positioning rather than being related to problems with the scanner hardware or software.

\section{Comparison of automated reports with expert manual review}

Having identified a lower sensitivity than expected in screening mode it was important to explore whether this was associated with a lack of image capture by the digital infrared scanner or if the artificial intelligence was sub optimal. Expert manual review showed that image capture was satisfactory with a sensitivity of $78 \%$ and a specificity of $48 \%$ for all patients. Final interpretation using a novel artificial intelligence software programme called NoTouch Breast Scan showed a marked uplift in sensitivity $(72 \%)$ and specificity (48\%) which is much closer to expert manual review. This shows much promise as these results may increase further when image capture is also performed with the NoTouch infrared scanner.

\section{Potential role for digital infrared breast scan}

Further analyses by age and method of interpretation provided key results that have helped to define the potential role for Digital Infrared BreastScan (DIB) for breast cancer detection (Table II). It is clear that the sensitivity in women over 70 years of age is low with all techniques and as a result DIB should not be recommended for this group. It is postulated that reduced vascularity in breasts of older women may account for the poor performance in this group. 
It has previously been suggested that DIB is as sensitive in younger women as it is in older women. In fact the results of this study show even better performance in women $<50$ years, compared with women aged 50-70 years, with a marked increase in both sensitivity (78\% vs. $72 \%$ ) and specificity (75\% vs. 37\%) using NoTouch software. This sensitivity was equal to the sensitivity of mammography in this group. The authors accept that these numbers are small, and the rise from $72 \%$ to $78 \%$ is not significant, but nevertheless these results support the use of NoTouch BreastScan to improve breast cancer detection in younger women where delays in diagnosis are more common [9]. The combination of NoTouch and mammography was even better with a combined sensitivity of $89 \%$ suggesting the way forward for a potential dual imaging approach in this younger age group. The high sensitivity overall for both mammography (89\%) and breast ultrasound (90\%) reflects the fact that this cohort all had a clinical or mammographic abnormality and imaging reporting was unblinded to the clinical findings.

\section{Comparison of digital infrared breast scan with conventional imaging}

There is currently much focus on improving the breast cancer detection rate in younger women where the sensitivity of mammography is low due to increased breast density. Although Breast MRI is more sensitive than mammography it is very expensive, requires highly skilled reporting and is not widely available in all hospitals. In contrast, DIB is cheap, scanners are mobile, reporting is semi-automated and minimal technical skills are required to perform these scans. As a result DIB could prove to be a useful adjunctive test to mammography in younger women or as an initial screening test in countries with no access to mammography. This is currently being addressed in ongoing studies in India.

The results of this study strongly suggest that recent improvements in digital image capture and artificial intelligence software have indeed contributed to increased performance when using DIB for breast cancer detection. These early results using NoTouch BreastScan are promising and further studies have been initiated to maximise performance with image capture as well as data interpretation. A key part of this will be to achieve a balance between sensitivity and specificity to improve the utility of DIB in clinical practise. 
In conclusion, the results of this study support the use of DIB as an effective adjunctive test for breast cancer detection in women under 70 years of age. DIB appears to be particularly effective in women under 50 years old where maximal sensitivity (78\%) and specificity (75\%) were observed. The combined sensitivity of NoTouch BreastScan and mammography in women under 50 was encouraging at $89 \%$, suggesting a potential way forward for a dual imaging approach in this younger age group. Further studies will explore the utility of DIB, with data capture and interpretation using NoTouch BreastScan, for breast cancer detection and monitoring response to neoadjuvant therapy.

\section{Acknowledgements}

GCW \& PDB receive research funding from the Cambridge NIHR Biomedical Research Centre.

\section{Sources of Funding}

The Sentinel BreastScan equipment was loaned by Infrared Sciences Corp. (Bohemia, NY, USA) to the research team for the duration of the study.

\section{Conflict of interest}

1. Matthew Campisi was a co-founder of Infrared Sciences Corp. but left the company in 2008. Since completion of this research study Matthew Campisi has joined UE LifeSciences Inc. (Philadelphia, PA, USA) to develop a commercial infrared breast scanner (NoTouch BreastScan).

2. Since completion of this research study BreastHealth UK (Cambridge, CAMBS, UK) has obtained UK distribution rights for NoTouch BreastScan. Gordon Wishart is a shareholder and co-founder of BreastHealth UK. 


\section{REFERENCES}

[1] Gotzsche PC \& Nielsen M. Screening for breast cancer with mammography. Cochrane database Syst Rev, CD001877.

[2] Joensuu H, Lehtmaki T, Holli K et al. Risk for distant recurrence of breast cancer detected by mammography screening or other methods. Jama 2004; 292: 1064-73.

[3] Shen Y, Yang Y, Inoue LY, Munsell MF, Miller AB, Berry DA. Role of detection method in predicting breast cancer survival: analysis of randomised screening trials. $\mathbf{J}$ Natl Cancer Inst., 2005; 97: 1195-203.

[4] Wishart GC, Greenberg DC, Britton PD, et al. Screen-detected vs symptomatic breast cancer: is improved survival due to stage migration alone? $\mathrm{Br} \mathrm{J}$ Cancer 2008; 98: 1741-4.

[5] Boyd NF, Byng JW, Jong RA, et al.: Quantitative classification of mammographic densities and breast cancer risk. J Natl Cancer Inst. 1995; 87:670-5.

[6] Lloyd-Williams K, Handley RS. Infra-red thermography in the diagnosis of breast disease. Lancet, 1961, 2; 1378-1381.

[7] Gamagami P: Indirect signs of breast cancer: Angiogenesis study. Atlas of Mammography. Cambridge, MA: Blackwell Science, 1996, pp.231-258.

[8] Arora N, Martins D, Ruggerio D et al. Effectiveness of a non-invasive digital infrared thermal imaging system in the detection of breast cancer. An J Surg., 2008; 196: 523-6

[9] Britton PD, Duffy S, Sinnatamby R et al. One-stop diagnostic breast clinics: how often are breast cancers missed? Br J Cancer 2009; 100: 1873-1878. 


\section{Table I}

Score in Sentinel screening mode for 65 malignant biopsies

\begin{tabular}{ccccccc}
\hline SCORE & $\mathbf{0}$ & $\mathbf{1}$ & $\mathbf{2}$ & $\mathbf{3}$ & $\mathbf{4}$ & $\mathbf{5}$ \\
\hline $\mathrm{n}$ & 30 & 13 & 9 & 11 & 2 & 0 \\
\hline
\end{tabular}


Table II

IR imaging by method of interpretation and age group

\begin{tabular}{|c|c|c|c|c|}
\hline & sensitivity & specificity & $\begin{array}{l}\text { Positive } \\
\text { Predictive } \\
\text { Value (PPV) }\end{array}$ & $\begin{array}{l}\text { Negative } \\
\text { Predictive } \\
\text { Value (NPV) }\end{array}$ \\
\hline $\begin{array}{l}\text { all patients } \\
(\mathrm{n}=106)\end{array}$ & & & & \\
\hline $\begin{array}{l}\text { sentinel } \\
\text { screening }\end{array}$ & $53 \%$ & $41 \%$ & $59 \%$ & $\%$ \\
\hline $\begin{array}{l}\text { sentinel neural } \\
\text { network }\end{array}$ & $48 \%$ & $74 \%$ & $73 \%$ & $48 \%$ \\
\hline $\begin{array}{l}\text { expert } \\
\text { manual review }\end{array}$ & $78 \%$ & $48 \%$ & 69 & $59 \%$ \\
\hline $\begin{array}{l}\text { no touch } \\
\text { patients }<\mathbf{5 0} \\
(\mathbf{n = 2 1})\end{array}$ & $70 \%$ & $48 \%$ & 679 & $51 \%$ \\
\hline $\begin{array}{l}\text { sentinel } \\
\text { screening }\end{array}$ & $67 \%$ & $67 \%$ & $60 \%$ & $72 \%$ \\
\hline no touch & $78 \%$ & $75 \%$ & $70 \%$ & $82 \%$ \\
\hline expert review & $78 \%$ & $75 \%$ & $70 \%$ & $82 \%$ \\
\hline $\begin{array}{l}\text { Patients 50-70 } \\
(n=73)\end{array}$ & & & & \\
\hline $\begin{array}{l}\text { sentinel } \\
\text { screening }\end{array}$ & $56 \%$ & $30 \%$ & $53 \%$ & $32 \%$ \\
\hline no touch & & $37 \%$ & $62 \%$ & $48 \%$ \\
\hline expert review & $83 \%$ & $36 \%$ & $67 \%$ & $61 \%$ \\
\hline
\end{tabular}




\section{Table III}

Sensitivity of IR imaging by tumour grade, type, size, nodal status and presence of lymphovascular invasion.

\begin{tabular}{|c|c|c|c|c|}
\hline \multirow[t]{2}{*}{ Characteristic } & \multicolumn{3}{|c|}{ No Touch BreastScan } & \multirow[t]{2}{*}{$P$ value } \\
\hline & $\begin{array}{l}\text { Number of } \\
\text { cancers }\end{array}$ & $\begin{array}{l}\text { Number of } \\
\text { positive } \\
\text { scans }\end{array}$ & Sensitivity & \\
\hline \multicolumn{5}{|l|}{ Age } \\
\hline$<\mathbf{5 0}$ & 9 & 7 & $78 \%$ & 0.40 \\
\hline $50-70$ & 43 & 31 & $72 \%$ & \\
\hline $70+$ & 12 & 5 & $42 \%$ & \\
\hline Tumour size & & & & \\
\hline$\leq \mathbf{2 c m}$ & 38 & 27 & $71 \%$ & 0.95 \\
\hline$>2-5 \mathrm{~cm}$ & 26 & 18 & $69 \%$ & \\
\hline \multicolumn{5}{|l|}{ Grade } \\
\hline 1 & 13 & 9 & $69 \%$ & 0.96 \\
\hline 2 & 35 & 25 & $71 \%$ & \\
\hline 3 & 14 & 10 & $71 \%$ & \\
\hline \multicolumn{5}{|l|}{ Nodal status } \\
\hline Negative & 31 & 20 & $65 \%$ & 0.63 \\
\hline Positive & 28 & 22 & $79 \%$ & \\
\hline $1-3$ & 24 & 19 & $79 \%$ & 0.98 \\
\hline 4-9 & 3 & 2 & $67 \%$ & \\
\hline $10+$ & 1 & 1 & $100 \%$ & \\
\hline \multicolumn{5}{|l|}{ Morphology } \\
\hline No specific type & 46 & 36 & $78 \%$ & 0.37 \\
\hline (ductal) & 2 & 0 & $0 \%$ & \\
\hline Lobular & 2 & 2 & $100 \%$ & \\
\hline Tubular & 3 & 0 & $0 \%$ & \\
\hline $\begin{array}{l}\text { Mixed } \\
\text { DCIS }\end{array}$ & 2 & 2 & $100 \%$ & \\
\hline \multicolumn{5}{|l|}{ Vascular invasion } \\
\hline Yes & 9 & 7 & $78 \%$ & 0.78 \\
\hline No & 51 & 34 & $67 \%$ & \\
\hline
\end{tabular}

\footnotetext{
* Lobular, tubular, mixed and DCIS pooled
} 


\section{Legends for Figures}

\section{Figure 1}

NoTouch Breast Scan in a 63 year old woman with a 30mm grade 3 invasive ductal cancer (no-specific type), with associated lymphovascular invasion, in the lower inner quadrant of the right breast. The right breast temperature is elevated (score 5) with a focal zone of increased vascularity at the site of the tumour.

\section{Figure 2}

NoTouch BreastScan in a 43 year old woman with a $15 \mathrm{~mm}$ grade 2 invasive ductal cancer (no specific type) in the upper outer quadrant of the right breast. The nipple temperature is elevated (score 4) and the upper scan shows an area that is reluctant to cool down at the site of the tumour despite good overall cooling of the breast from $31.6 \mathrm{C}$ to $28.2 \mathrm{C}$. 


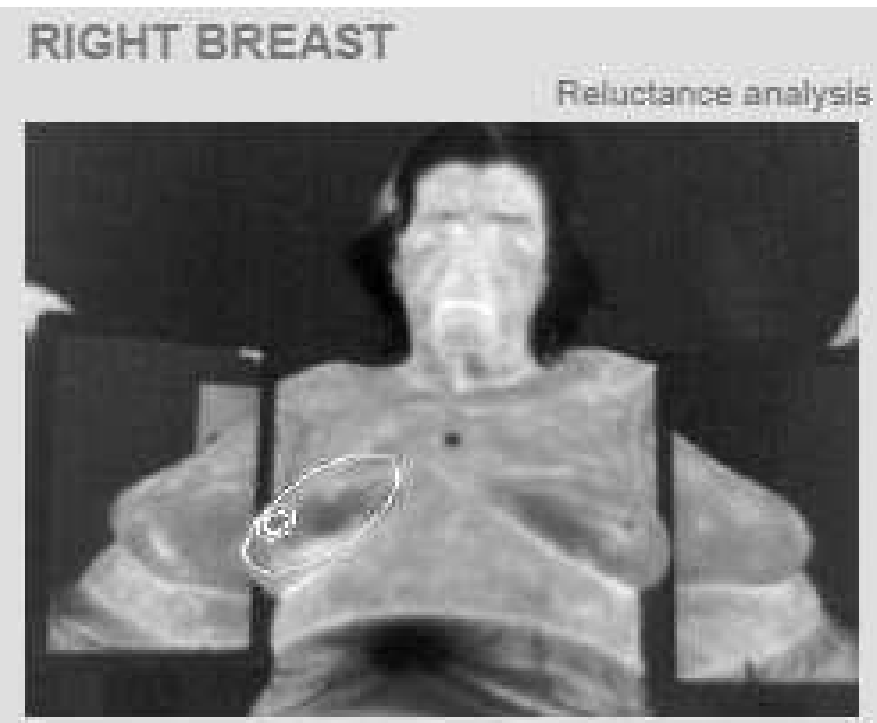

Vascularity and Hot Zone analysis

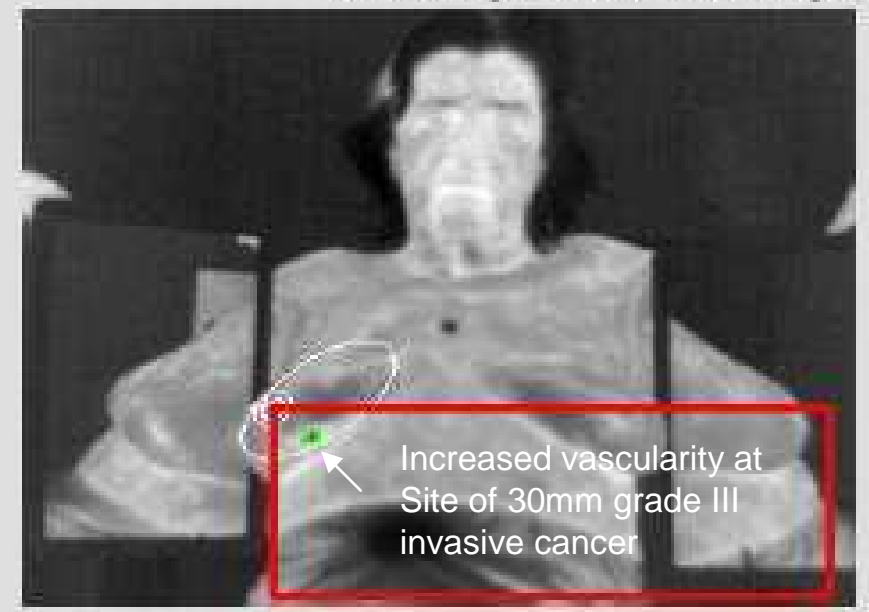

Cooled from $34.5 \mathrm{C}$ to $32.5 \mathrm{C}$

Difference is 2.00

Nipple

Full Breast 5

iMeasure 


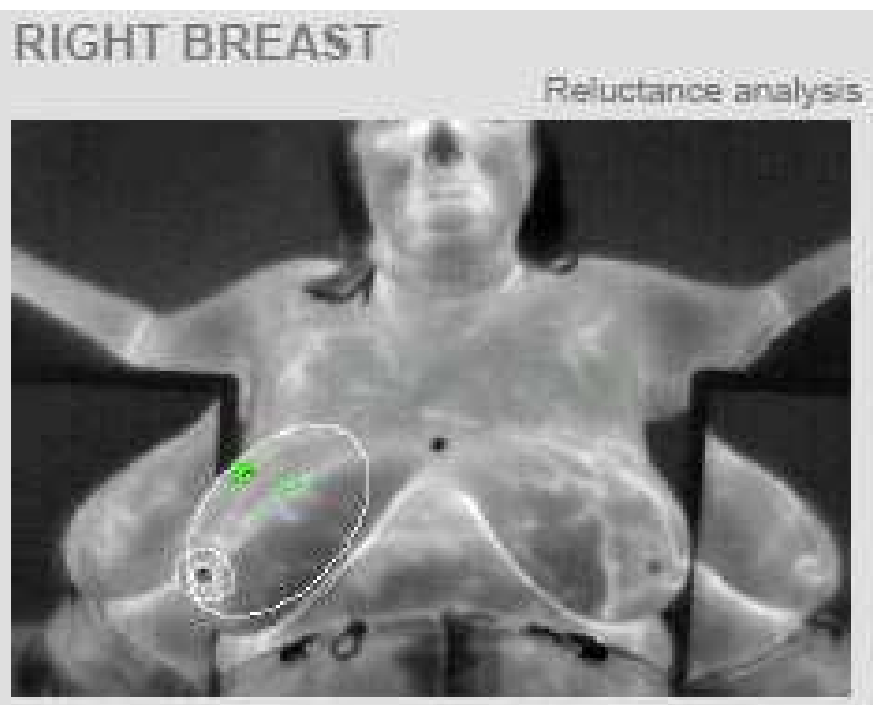

Vascularity and Hot Zone analysis

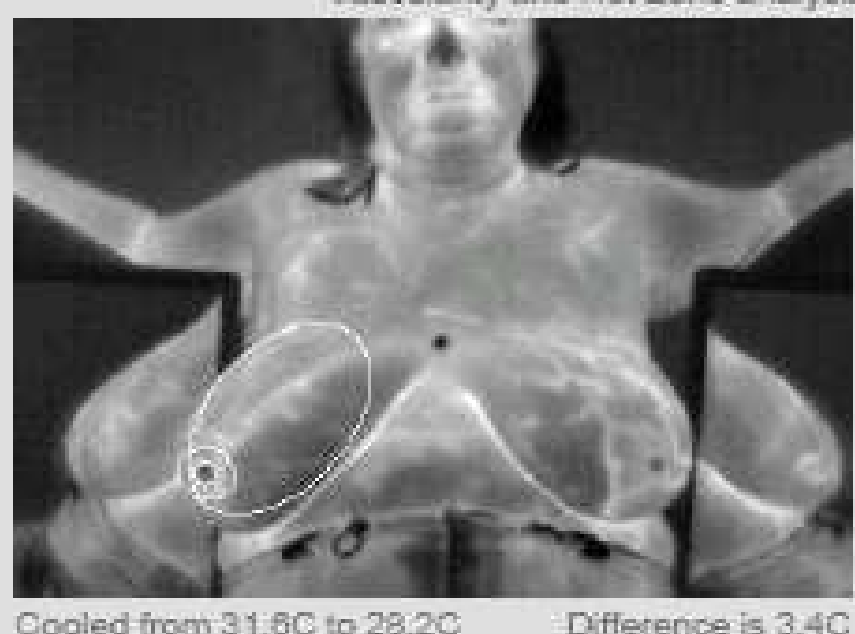

Cooled from $31.8 \mathrm{C}$ to $28.2 \mathrm{C}$

Difference is 3.40

Nipple 4 Full Bereast.

iMeasure : 4 